\title{
Design and Implementation of a Home Security System Based on Solar Energy
}

\author{
Anas S. Saif: Mohammed H. Alshemasi; Ahmed A Abouelfadl \\ Department of electrical engineering, King Abdulaziz University, Rabigh, KSA \\ Eng.anas.99.saif@gmail.com: Mohamed45443@gmail.com; aabouelfad@kau.edu.sa
}

DOI: 10.26821/IJSHRE.9.4.2021.9408

\begin{abstract}
In this paper, a home security system based on solar energy has been designed and implemented with high security and low cost as much as possible. It has been done by using electronic four electronic sensors which are a flame sensor, gas sensor, motion sensor, and rain sensor to protect a home from risks, such as thefts, rains, gas leakage, and fires. Also, it has been improved by using solar energy and a global system for mobile communication (GSM). A microcontroller is used to control inputs and outputs of the system. The Proteus Program was used in the simulation by using C-language. A project has been implemented as a prototype.
\end{abstract}

Keywords: Home Security; Solar Energy, Microcontroller; GSM unite; Sensors.

\section{INTRODUCTION}

Home security systems are substantial in life to keep people and things are safe. That is why wireless home security systems or home automation systems are a process for improving the quality of resident's life by facilitating a flexible, comfortable, and secure environment [1]. The earliest home security systems back to the 1900s. These systems were expensive and hard to monitor [2]. Home security systems have changed a great deal over the last century and will continue to do so if technology continues to progress [3]. Nevertheless, we have designed and implemented a home security system to protect homes from risks, such as thefts, rains, gas leakage, and fires which are the most important requirements of a perfect home security system. Also, solar energy has been made the home security system more efficient, so it does not dependent on power plants at all. Besides that, using GSM has been done to make the project easy to monitor.

\section{IDEA OF THE HOME SECURITY SYSTEM}

\subsection{Block Diagram}

A general block diagram of the proposed home security system is shown in Fig.1 for representing sensors' actions. There are four sensors that have different reactions.

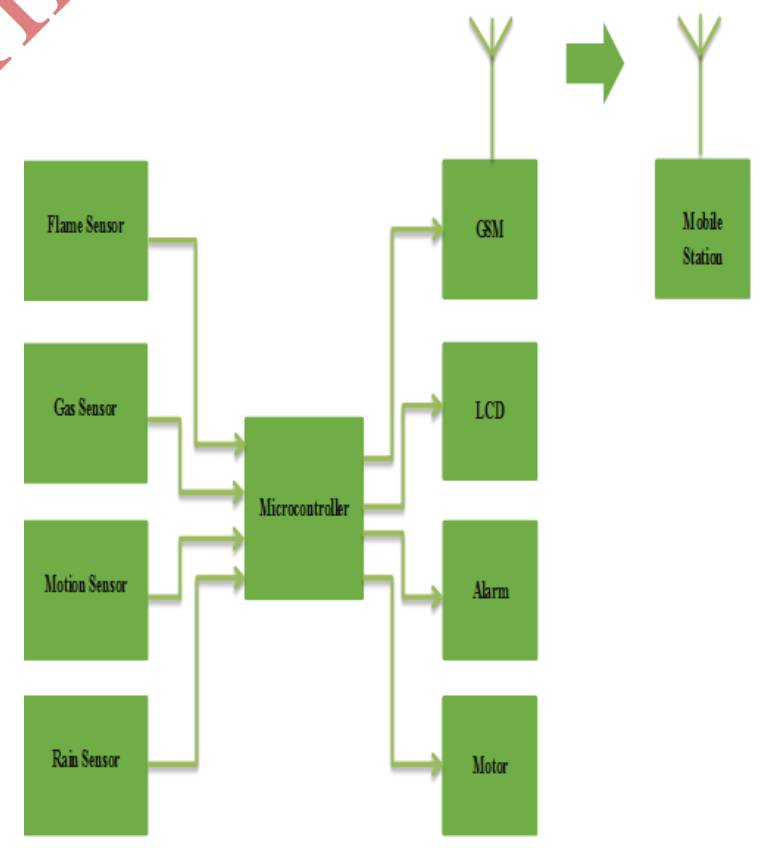

Fig. 1 Block Diagram of the system.

\subsection{Design of the System}

The implementation of a practical circuit has been designated by Proteus Software as shown in Fig.2.The system has been implemented by four sensors that were used to protect homes. In 
iJournals: International Journal of Software \& Hardware Research in Engineering (IJSHRE)

ISSN-2347-4890

Volume 9 Issue 4 April 2021

addition, a microcontroller has been used for controlling all sensors to do specific functions when the sensors detect something dangerous at home. Also, GSM was used for warning owners or

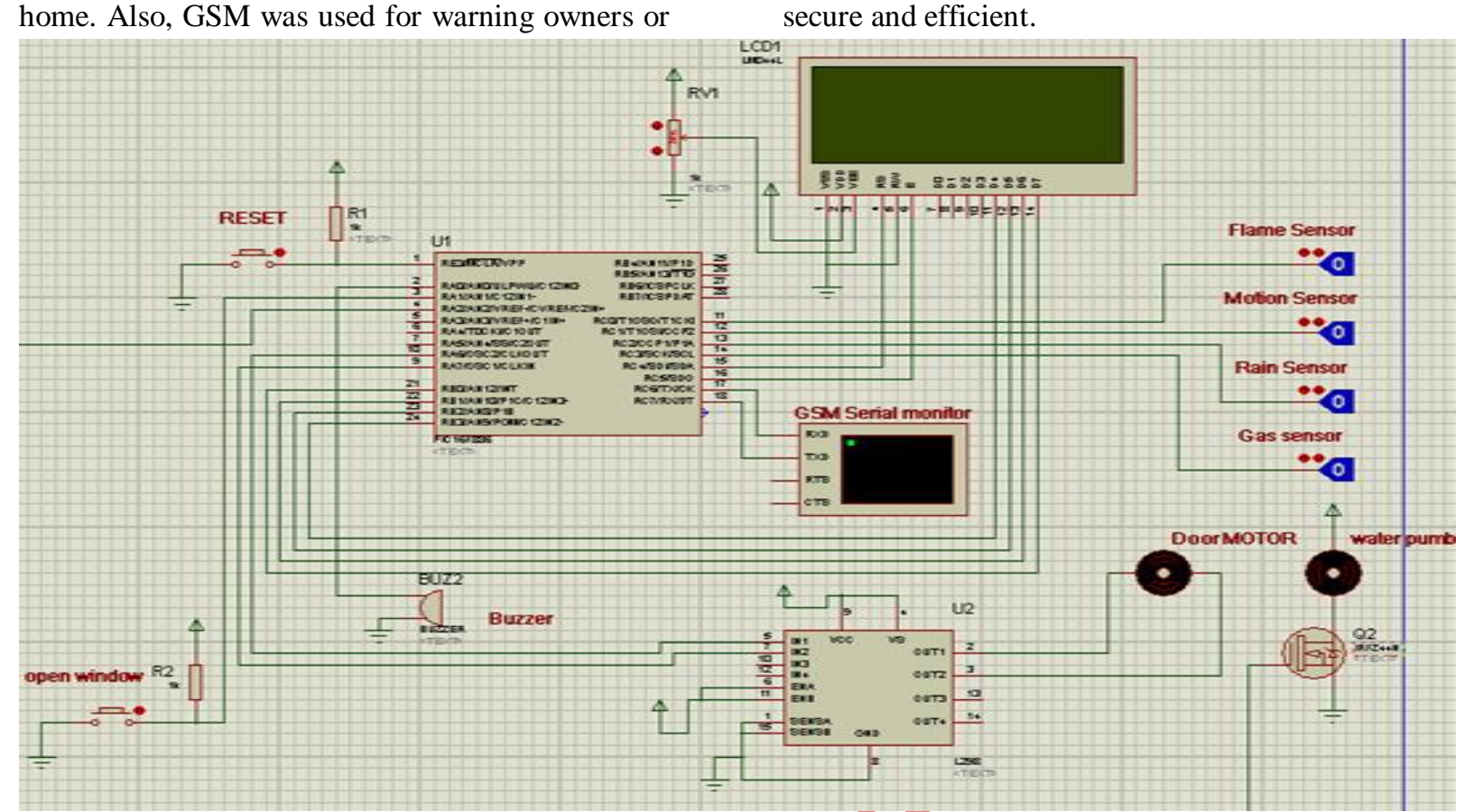

Fig. 2 Proetus implementation design of the security system

A flow chart of the system operation is shown in Fig. 3 that represents the sensors' reactions in detail. The microcontroller is programed

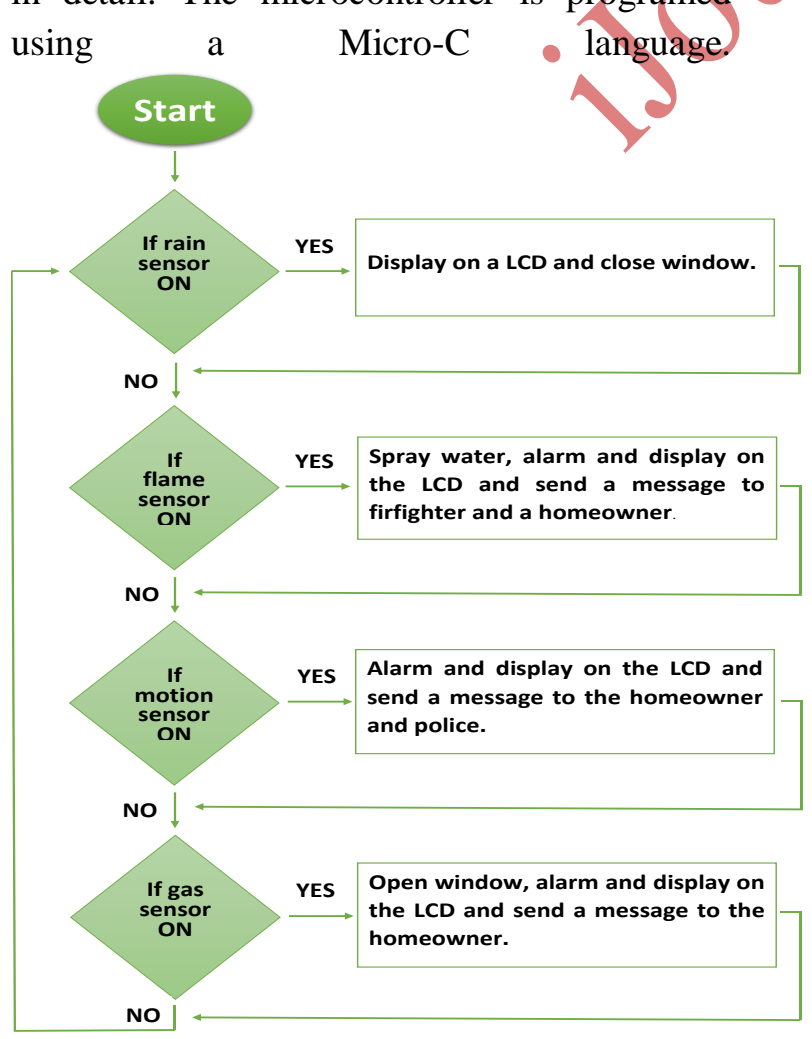

Fig. 3 Flaw chart of the system operation government agencies to be ready to minimize the risk at home as soon as possible. Besides, solar secure and efficient. energy was used for making the system more

\subsection{Main components of the system}

\subsubsection{Solar energy system}

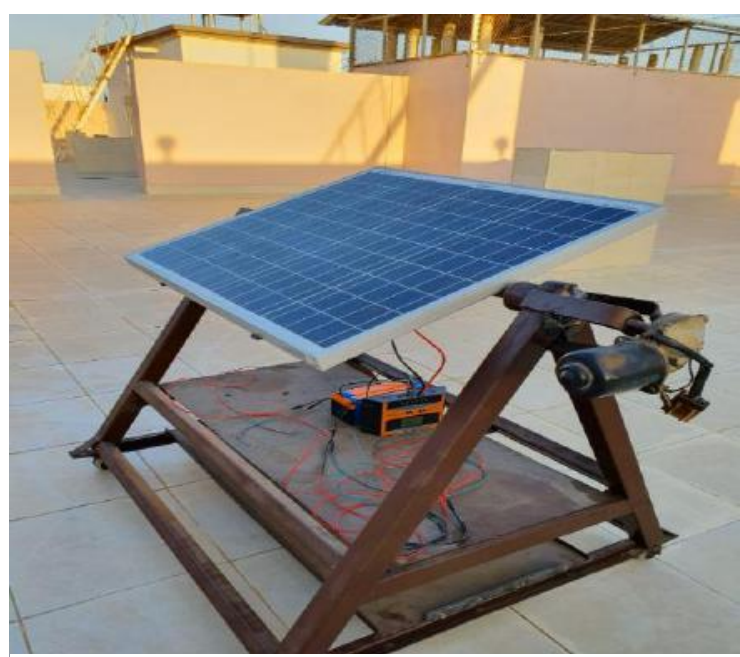

Fig.4: Implementation of the PV system.

The solar energy system consists of a PV solar kit, charger controller and solar battery as shown in Fig.4.

\subsubsection{Flame sensor}

A flame sensor has been used as shown in a Fig.5 to protect a home from fire. If there is a fire at home, the flame sensor detects that, so it protects 
Volume 9 Issue 4 April 2021

the homes by opening a sprinkler after a few seconds because it minimizes the fire by spraying water. Also, the flame sensor has related to an alarm device, GSM and liquid crystal display (LCD) to alert a homeowner. However, if there is a fire, the flame sensor sends a signal to the

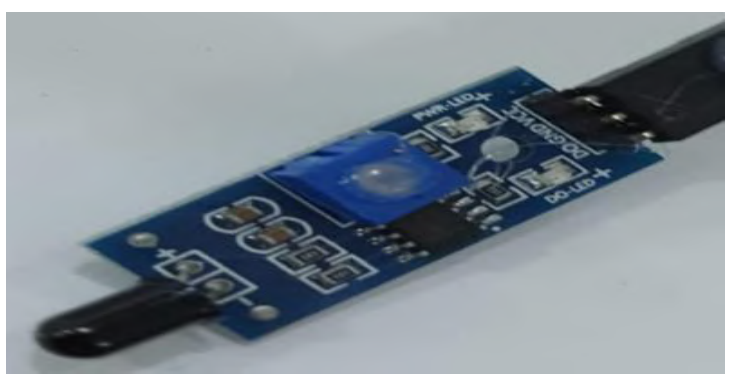

Fig.5: The flame sensor.

microcontroller. After that, the microcontroller will send the signal to the sprinkler to minimize the fire as much as it can. Also, it is shown on the LCD that " fire detected " to alert others who live at home as well.

\subsubsection{Gas sensor}

A gas sensor (MQ-2) has been used as shown in a Fig. 6 to protect the homes from gas leakage. If there is a gas leakage, windows are opened automatically. Also, it has been shown a type of danger on the LCD if there is a gas leakage to alert the homeowner. In addition, it has related to the alarm device and GSM to alert others too. However, if there is a gas leakage, the gas sensor sends a signal to the microcontroller. After that, the microcontroller will send the signal to a DC motor to open windows that exit the gas leakage outside.

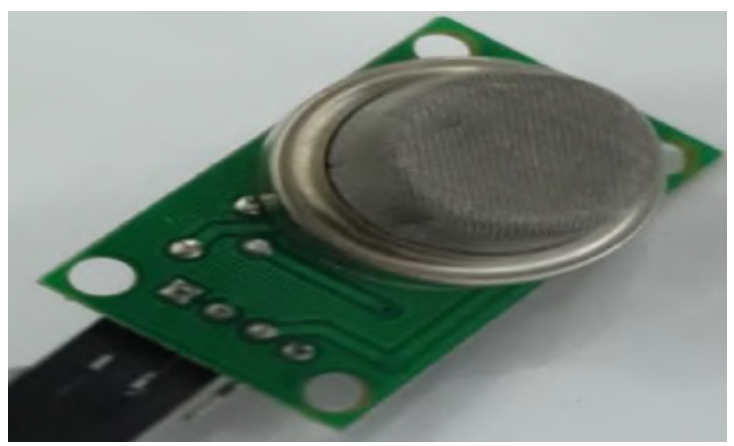

Fig.6 Gas senor

\subsubsection{Motion sensor}

A motion sensor PIR (HC-SR-501) has been used as shown in a Fig.7 to protect the homes from thieves. It has related to the alarm device. Also, it has related to the LCD to show a type of danger to alert people who live at home. Besides that, it has related to the GSM to alert the homeowner by an SMS message that reaches immediately. However, if there is a thief at home, the motion sensor sends a signal to the microcontroller. After that, the microcontroller will send the signal to the alarm device, LCD and GSM to take different reactions.

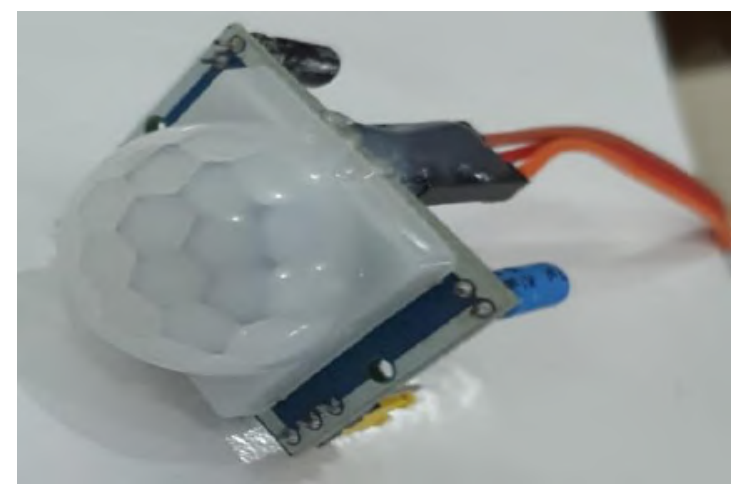

Fig.7 The motion sensor.

\subsubsection{Rain sensor}

A rain sensor (FC-37) has been used as shown in a Fig.8 to protect the homes from rain. If there is rain, windows are closed automatically, and it has been shown on the LCD "rain detected". Also, it has related to the GSM to alert the homeowner. However, if it rains, the rain sensor sends a signal to the microcontroller. After that, the microcontroller will send the signal to the DC motor to close the windows for protecting the home.

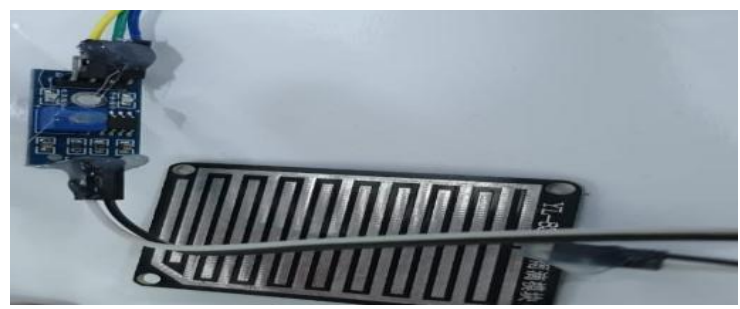

Fig. 8 Rain Sensor

\subsubsection{Microcontroller}

A microcontroller (PIC16F886) has been used as shown in a Fig.9. It is the man part of the project that uses for controlling the whole system because it sends signals to all devices to do specific reactions to minimize the risks at home. If one of the sensors detects any risk at home, the microcontroller sends signals to the devices. The GSM module, water pump, and DC motor are devices that do reactions if there is any risk at home. However, input DC voltage of the 


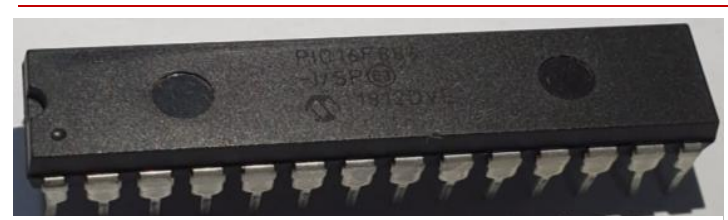

Fig.9 Microcontroller

PIC16F886 is $5 \mathrm{~V}$ and current drawn is $20 \mathrm{~mA}$, so power consumed by the PIC16F886 is only $5 \mathrm{~V} \times$ $20 \mathrm{~mA}=0.1 \mathrm{~W}$.

\subsubsection{GSM module}

The GSM module has been used as shown in a

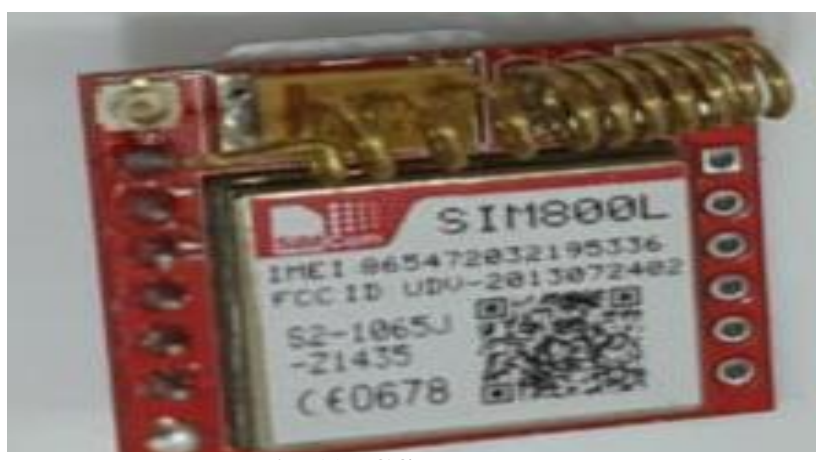

Fig.10: GSM module.

Fig.10. It is responsible for connecting to a homeowner's phone or other people who can minimize or prevent the problems at home by sending a warning message. However, operating voltage of the GSM module is 4 VDC and operating current of the GSM module is $15 \mathrm{~mA}$, so power consumed in the GSM module is just $15 \mathrm{~mA}$ $\times 4 \mathrm{~V}=0.06 \mathrm{~W}$.

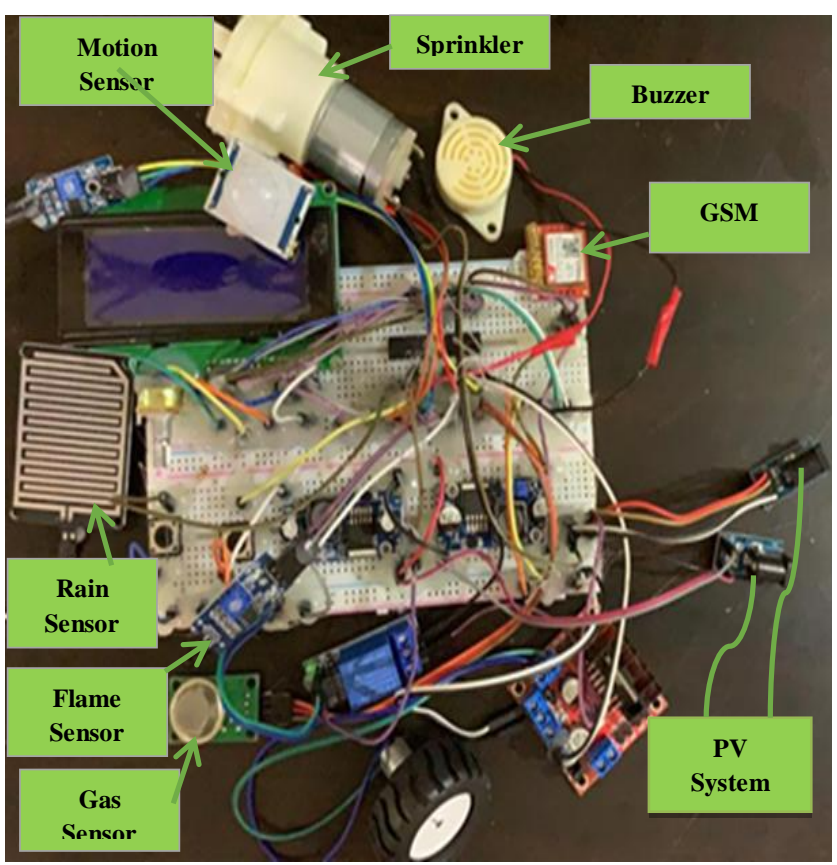

Fig.11 The practical circuit.

\section{SYSTEM PRCATICAL PROTOTYPE}

The circuit of the security system has been implemented as a prototype as shown in a Fig. 11. The system has been tested and operated.

\section{CONCLUSION}

No one can deny that the home security system is extremely important in life. The simulation in the Proteus Program, flow chart and block diagram of the project were represented the idea. The microcontroller was used to control all sensors and it does not use a crystal oscillator because it has an internal oscillator by default. The LCD that was used has four rows and twenty items to allow more information that was shown on the display screen if the four risks occurred at the same time. There was only one DC motor with a motor driver to allow the DC motor to move in two directions for opening and closing the windows. The buzzer that was used has input DC range of voltages $\mathrm{Vcc}=[3 \mathrm{Volt}-24$ Volt]. If the magnitude of the buzzer's voltage increases, the sound of the buzzer increases too. Finally, power has been driven from the solar system.

\section{REFERENCES}

[1]. Rana, G.M.S.M., Khan, A.A.M., Hoque, M.N. and Mitul, A.F.,'Design and Implementation of a GSM Based Remote Home Security and Appliance Control System", Proceedings of the 2nd International Conference on Advances in Electrical Engineering, Dhaka, 19-21 December 2013, 291-295

[2]. Ibrahim Geha, Kfoury Elie, and Ashraf Jaafar, "SAFE HOMEC An Advanced Home Security System”, Department of Mechanical Engineering American University of Beirut Beirut, Lebanon, Volume 2, 2009 , pp 234239.

[3]. The History of Home Security 4th July2010[Online]. Available: http://ezinearticles.com. 